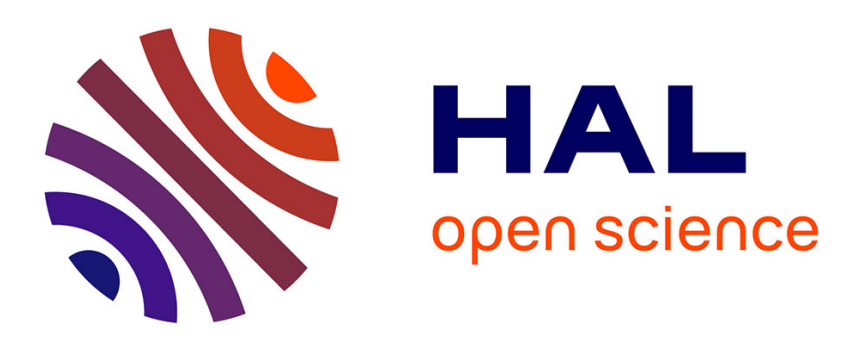

\title{
Doped carbon nanostructure for cold-field emission guns: Structural and EELS studies
}

Rongrong Wang, Aurélien Masseboeuf, David Neumeyer, Marc Monthioux, Alejandro Lopez-Bezanilla, Raul Arenal

\section{- To cite this version:}

Rongrong Wang, Aurélien Masseboeuf, David Neumeyer, Marc Monthioux, Alejandro Lopez-Bezanilla, et al.. Doped carbon nanostructure for cold-field emission guns: Structural and EELS studies. Nanotechnology Materials and Devices Conference (NMDC), 2016 IEEE, Oct 2016, Toulouse France. pp.1-2, 10.1109/NMDC.2016.7777065 . hal-01430581

\section{HAL Id: hal-01430581 https://hal.science/hal-01430581}

Submitted on 7 Mar 2018

HAL is a multi-disciplinary open access archive for the deposit and dissemination of scientific research documents, whether they are published or not. The documents may come from teaching and research institutions in France or abroad, or from public or private research centers.
L'archive ouverte pluridisciplinaire HAL, est destinée au dépôt et à la diffusion de documents scientifiques de niveau recherche, publiés ou non, émanant des établissements d'enseignement et de recherche français ou étrangers, des laboratoires publics ou privés. 


\section{Doped carbon nanostructure for Cold-Field Emission Guns: Structural and EELS studies*}

Along with the development of the transmission electron microscope (TEM), cold field emission gun (C-FEG) becomes more and more popular. As a result of working at ambient temperature $(300 \mathrm{~K})$, the C-FEG can offer narrower electron beam energy spread than that of Schottky gun [1]. Such a low working temperature also permits a smaller emission area. From Fowler-Nordheim (F-N) equation (1), the three tailorable parameters play a pivotal role to achieve better performances. They are the emission area A, the work function $\mathrm{W}$ and the field enhancement factor $\gamma$ :

$$
\mathrm{I}=\frac{\mathrm{aA} \gamma^{2} \mathrm{~V}^{2}}{\mathrm{Wd}^{2} \mathrm{t}^{2}(\mathrm{y})} \exp \left(\frac{-\mathrm{bdf}(\mathrm{y}) \mathrm{W}^{3 / 2}}{\gamma \mathrm{V}}\right)
$$

The field enhancement factor can be raised by reducing the apex radius of emitter. In $\mathrm{C}-\mathrm{FEG}$, the apex radius of $\mathrm{W}$ (310) emitter is only $10 \%$ of $\mathrm{ZrO}$ coated $\mathrm{W}(100)$, which is used in Schottky gun. Consequently, the spatial coherence of electron beam is extremely enhanced [2]. In recent studies, the carbon nanotubes (CNTs) are considered as a better emitter [3]. Due to their quasi one-dimension structure, the oriental $\sigma$ bonds offer a high mechanical performance along the axis direction [4]. This makes them capable of resisting the strong electrostatic force under the cold field emission condition. Their high melting point allows them to be degassed by the classical flash procedure. The chemical inert surface can keep their surface clean. In addition, their high carrier mobility enables to bear a higher current density [5]. More recently, the carbon cone nanotips (CcNTip) are considered even better than the CNTs [6]. Their root at micrometer level is more convenient for their manipulation and installation and more stable against external vibrations. As their apex radius is around $5 \mathrm{~nm}$, the great spatial coherence of electron beam has been proved, and a higher resolution electron holography can be expected [7].

Besides the enhancement factor and the emission area, the work function is a key factor to achieve high electron beam brightness as well. Doping is an effective method to lower the work function of nanomaterials [8]. In the wake of doping with foreign atoms, the local electric field is tailored, which is also reflected in the band structure modification. Concerning carbon nanomaterials, boron and

$\square *$ Research supported by ANR, ESTEEM2 and TALEM.

R. Wang is with the CEMES, Univ. Toulouse, CNRS UPR 8011, Toulouse, 31400 France and the LMA-INA, Univ. Zaragoza, Zaragoza, 50018 Spain (rongrong.wang@cemes.fr).

A. Masseboeuf, D. Neumeyer, M. Monthioux are with the CEMES, Univ. Toulouse, CNRS UPR 8011, Toulouse, 31400 France.

A. Lopez-Bezanilla is with the Materials Science Div., Argonne National Lab., Illinois, IL 60439 USA.

R. Arenal is with the Fundacion ARAID, Zaragoza, 500018 Spain and the LMA-INA, Univ. Zaragoza, Zaragoza, 50018 Spain (arnal@unizar.es). nitrogen are frequently used to modulate their band structure [9-11]. However, the influence of these dopants strongly depends on their position and atomic configuration, i.e. the graphitic nitrogen doping can create the donor state near the Fermi level by reason of the contribution of the excess electrons to the conjugated bond system [12]. On the contrary, pyridinic and pyrrolic nitrogen create the acceptor state near the Fermi level [9]. In the substitutional nitrogen doping case, the up-shifted Fermi level will bring about a lowered work function. Therefore, a higher emission current density can be expected. In this work, the electronic properties of these kinds of carbon nanostructures, used as high performance cold cathodes in TEM, were adjusted by BN co-doping. This co-doping was investigated by different characterization techniques.

In order to avoid introducing additional defects into the CcNTip's lattice and forming bamboo-like structure, the post-growth doping method was considered as the most suitable candidate. On the account of the relative low CcNTip production and the highly similar structure with the CNTs, this research was started from the doping of the CNTs. The CNTs were doped in a tubular furnace from $1300^{\circ} \mathrm{C}$ to $1500^{\circ} \mathrm{C}$ under the various atmospheres. The high resolution TEM imaging (HRTEM) investigated the structural influence from the thermal treatment (Fig. 1). Due to the good thermal resistance of CNTs, there is no significant structural modification observed. Spatially-resolved electron energy loss spectroscopy (SR-EELS), developed in a scanning TEM (STEM), confirmed the generation of BN nanodomain inside

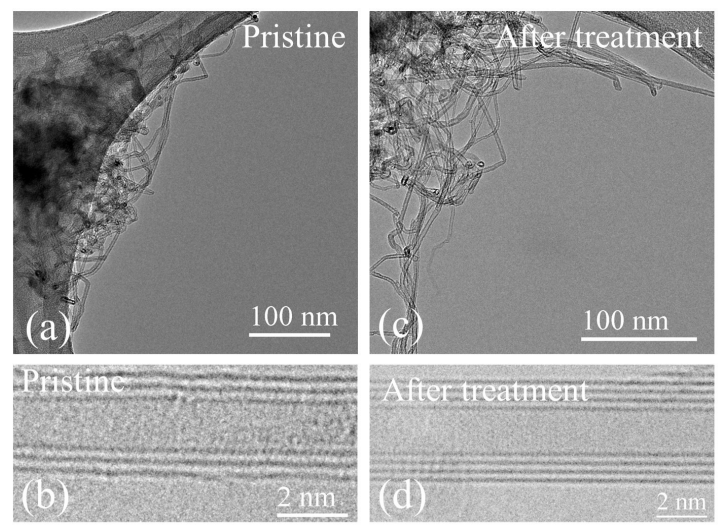

Figure1. Structural comparison between pristine (a), (b) and doped CNTs (c), (d) at different magnification. layer inside the CNTs shows the generation of BN@CNT hybrid nanotubes. Those TEM based studies were developed by employing two different aberrations corrected TEMs (FEI-Titan), working at low acceleration voltage $(80 \mathrm{kV})$ in order to prevent the nanotubes from the damage caused by the electronic irradiation. Moreover, the formations of $\mathrm{C}-\mathrm{B}$ bonding and $\mathrm{C}-\mathrm{N}$ bonding are macroscopically confirmed by $\mathrm{X}$-ray photoelectron spectroscopy (Fig. 3). The electronic 
property of such a kind of doped device and the influence of

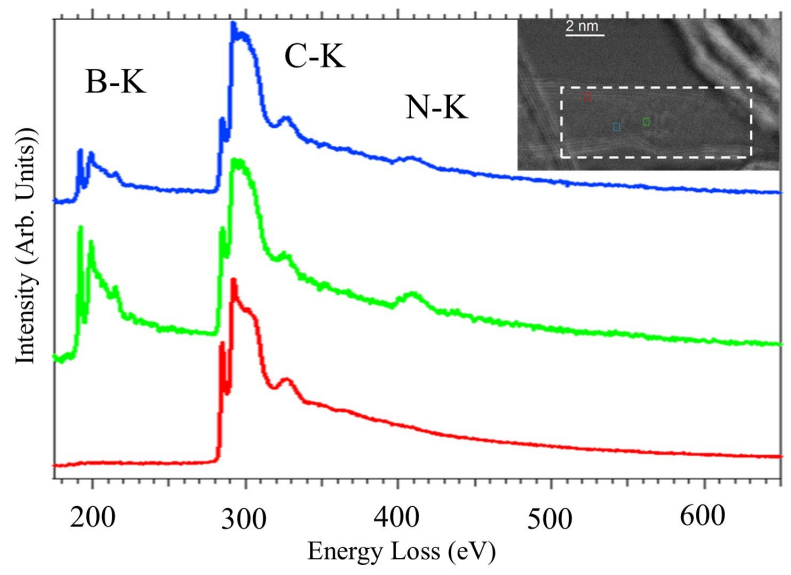

Figure2. Selection of EEL spectra extracted from the spectra image; blue, red and green spectra correspond to the pixels outlined in blue, red and green in insert image.

the introduced hetero-elements is clarified by the DFT calculations. All these results will be discussed in depth in this contribution.

\section{AcKNowledgment}

This work was supported by the project ANR LASCAR

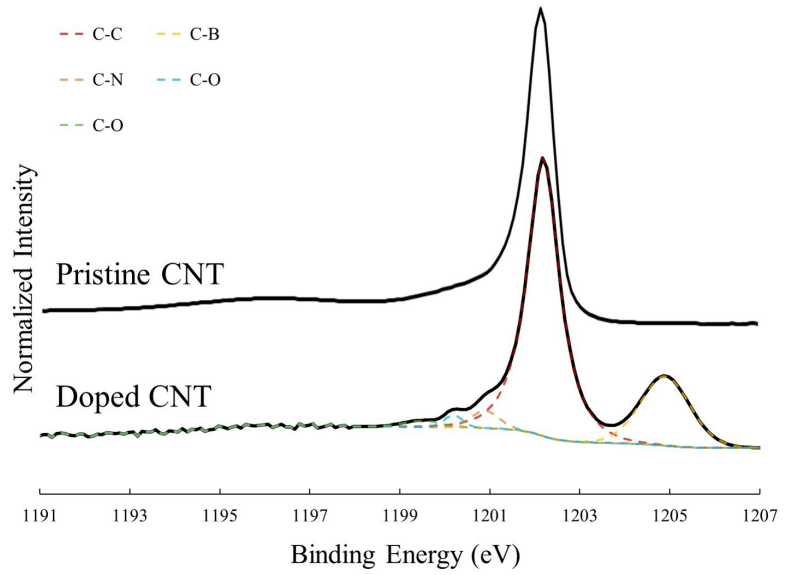

Figure3. XPS spectra of carbon C1s binding energy for pristine CNT and Doped CNT

(ANR-13-BS04-0007), by the European Union Seventh Framework Program under Grant Agreement 312483 ESTEEM2 (Integrated Infrastructure Initiative - I3), and by the international associated laboratory TALEM (CNRS - U. of Zaragoza). TEM studies were developed in the Advanced Microscopy Laboratory (LMA) of Institute of Nanoscience of Aragon (INA) - U. of Zaragoza (Spain). R.A. acknowledges funding from the Spanish Ministerio de Economia y Competitividad (FIS2013-46159-C3-3-P) and from the European Union H2020 programs ETN project "Enabling Excellence" Grant Agreement 642742 and "Graphene Flagship" Grant Agreement 696656.

\section{REFERENCES}

[1] Y. Kohno, E. Okunishi, T. Takeshi, I. Isamu, K. Toshikatsu, O. Yoshihiro, Y. Kondo, and T. Isabell, "Development of a Cold FieldEmission Gun for a $200 \mathrm{kV}$ Atomic Resolution Electron Microscope," Microscopy and Analysis, vol. 24, no. 7, pp. S9-S13, Jun. 2013.

[2] A. Tonomura, Electron Holography, vol. 70. Berlin, Heidelberg: Springer Berlin Heidelberg, 1999.

[3] X. Q. Wang, M. Wang, P. M. He, Y. B. Xu, and Z. H. Li, "Model calculation for the field enhancement factor of carbon nanotube," Journal of Applied Physics, vol. 96, no. 11, pp. 6752-6755, Dec. 2004.

[4] J.-P. Salvetat, G. A. D. Briggs, J.-M. Bonard, R. R. Bacsa, A. J. Kulik, T. Stöckli, N. A. Burnham, and L. Forró, "Elastic and Shear Moduli of Single-Walled Carbon Nanotube Ropes," Phys. Rev. Lett., vol. 82, no. 5, pp. 944-947, Feb. 1999.

[5] T. Dürkop, S. A. Getty, E. Cobas, and M. S. Fuhrer, "Extraordinary Mobility in Semiconducting Carbon Nanotubes," Nano Lett., vol. 4 no. 1, pp. 35-39, Jan. 2004

[6] F. Houdellier, L. de Knoop, C. Gatel, A. Masseboeuf, S. Mamishin, Y. Taniguchi, M. Delmas, M. Monthioux, M. J. Hÿtch, and E. Snoeck, "Development of TEM and SEM high brightness electron guns using cold-field emission from a carbon nanotip," Ultramicroscopy, vol. 151, pp. 107-115, Apr. 2015.

[7] F. Houdellier, A. Masseboeuf, M. Monthioux, and M. J. Hÿtch, "New carbon cone nanotip for use in a highly coherent cold field emission electron microscope," Carbon, vol. 50, no. 5, pp. 2037-2044, Apr. 2012.

[8] J. D. Wiggins-Camacho and K. J. Stevenson, "Effect of Nitrogen Concentration on Capacitance, Density of States, Electronic Conductivity, and Morphology of N-Doped Carbon Nanotube Electrodes," J. Phys. Chem. C, vol. 113, no. 44, pp. 19082-19090, Nov. 2009.

[9] P. Ayala, R. Arenal, A. Loiseau, A. Rubio, and T. Pichler, "The physical and chemical properties of heteronanotubes," Rev. Mod. Phys., vol. 82, no. 2, pp. 1843-1885, Jun. 2010.

[10] R. Arenal, X. Blase, A. Loiseau, "Boron-nitride and boroncarbonitride nanotubes: synthesis, characterization and theory", Advances in Physics 59, 101 (2010).

[11] P. Ayala, R. Arenal, M. Rümmeli, A. Rubio, and T. Pichler, "The doping of carbon nanotubes with nitrogen and their potential applications" Carbon 48 (3), 575-586, 2010.

[12] R Arenal, K March, CP Ewels, X Rocquefelte, M Kociak, A Loiseau, O. Stephan, "Atomic configuration of nitrogen-doped single-walled carbon nanotubes", Nano letters 14 (10), 5509-5516 (2014).

[13] R. Wang, A. Masseboeuf, M. Monthioux, A. Lopez-Bezanilla and R. Arenal, submitted (2016). 